\title{
LOCAL / DISTORTIONAL / GLOBAL MODE COUPLING IN FIXED LIPPED CHANNEL COLUMNS: BEHAVIOUR AND STRENGTH
}

\author{
Pedro B. Dinis ${ }^{1}$, Dinar Camotim ${ }^{1,}$, Eduardo M. Batista ${ }^{2}$ and Eliane Santos ${ }^{2}$ \\ ${ }^{1}$ Department of Civil Engineering and Architecture, ICIST/IST, Technical University of Lisbon, Portugal \\ ${ }^{2}$ Civil Engineering Program, COPPE, Federal University of Rio de Janeiro, Brazil \\ *(Corresponding author: E-mail: dcamotim@civil.ist.utl.pt)
}

\begin{abstract}
This paper reports the available results of an ongoing numerical and experimental investigation on the post-buckling behaviour and strength of fixed-ended cold-formed steel lipped channel columns affected by local/distortional/global (flexural-torsional) mode interaction. Initially, ABAQUS shell finite element results concerning columns exhibiting identical local, distortional and global buckling loads (their geometries are identified through preliminary buckling analyses) are presented and discussed - otherwise identical columns containing critical-mode initial geometrical imperfections with different configurations are analysed. These numerical results include (i) elastic and elastic-plastic post-buckling equilibrium paths, (ii) curves and figures providing the evolution, along a given path, of the column deformed configuration and (iii) the characterisation of the column collapse mechanism. Then, the paper addresses the experimental investigation currently under way at COPPE (Federal University of Rio de Janeiro) and to be fully reported in the near future experimental and numerical results concerning one test are presented and discussed. Finally, the paper closes with some preliminary considerations concerning the applicability of the current Direct Strength Method (DSM) expressions to estimate the ultimate strength of cold-formed steel lipped channel columns experiencing local/distortional/global buckling mode interaction.
\end{abstract}

Keywords: Lipped channel columns, Local/distortional/global mode interaction, Post-buckling behaviour, Shell finite element analysis, Experimental analysis, Ultimate strength, Direct Strength Method (DSM)

\section{INTRODUCTION}

Most cold-formed steel members display very slender thin-walled open cross-sections, a feature making them highly susceptible to several instability phenomena, namely local, distortional and global (flexural or flexural-torsional) buckling (see Figures 1(a)-(d)) - depending on the member length and cross-section shape/dimensions, any of these buckling modes may be critical. Since commonly used cold-formed steel member geometries may lead to similar local, distortional and global buckling stresses, the associated post-buckling behaviour, ultimate strength and collapse mechanism are likely to be strongly affected by interaction phenomena involving those buckling modes.

(a)

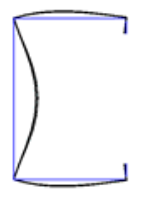

(b)

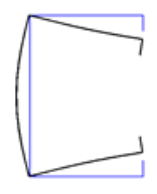

(c)

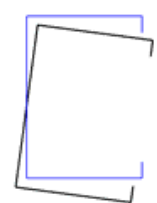

(d)

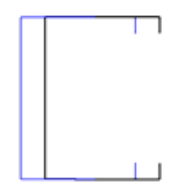

Figure 1. (a) Local, (b) Distortional, (c) Flexural-torsional and (d) Flexural Buckling (Lipped Channel Section)

It is well known that thin-walled members exhibit stable local and global post-buckling behaviours with high and low post-critical strength reserve. On the other hand, recent studies (e.g., Prola and Camotim [1] and Silvestre and Camotim [2]) showed that the distortional post-buckling behaviour fits in between the previous two and exhibits a non-negligible asymmetry with respect to the flange-lip motion (outward or inward). 
Amongst the mode interaction phenomena affecting the column post-buckling behaviour, those stemming from the nearly simultaneous occurrence of local and global buckling are, by far, the better understood indeed, virtually all current hot-rolled and cold-formed steel design codes account for them, either through the "plate effective width" concept (e.g. Batista [3]) or by means of the increasingly popular "Direct Strength Method" (e.g. Schafer [4, 5]). As for the local/distortional interactive buckling of lipped channel columns, it has attracted the attention of several researchers in the recent past: both numerical and experimental investigations have been reported (e.g. References [6-20]), and some of this work already led to the proposal of novel Direct Strength Method approaches to account for this phenomenon [8-15, 18, 20]. Concerning the coupling phenomena involving both distortional and global buckling (distortional/global and local/distortional/global interaction) in cold-formed steel members, the available literature is much more scarce. Indeed, the authors are only aware of some recent publications, mostly dealing with cold-formed carbon steel lipped channel columns: (i) numerical analysis of simply supported columns [21-25] and (ii) both numerical and experimental studies on fixed-ended columns [26] - the few exceptions correspond to numerical analyses of stainless steel lipped channel columns [27] and carbon steel rack-section columns [28]. The aim of the authors' current research effort, which is partially reported in this paper, is to investigate, both numerically and experimentally, the post-buckling behaviour and ultimate strength of fixed-ended carbon steel lipped channel columns affected by local/distortional/global interaction.

The first part of the paper deals with the presentation and discussion of numerical results concerning the (i) elastic and elastic/perfectly-plastic post-buckling behaviour, (ii) ultimate strength and (iii) failure mode nature of cold-formed steel ( $E=210 \mathrm{GPa}, v=0.3$ ) fixed-ended lipped channel columns with cross-section dimensions and lengths leading to virtually coincident local (L), distortional (D) and global (G) buckling loads - the identification of these column geometries requires the performance of preliminary buckling analyses. One analyses a fairly large number of columns that differ only in the initial geometrical imperfection shape - the various configurations dealt with are linear combinations of the competing L, D and $\mathrm{G}$ buckling modes, normalised to exhibit amplitudes equal to $10 \%$ of the wall thickness $t$ (local and distortional modes) and $0.1 \%$ of the column length $L$ (global mode). All the numerical results presented were obtained through finite element analyses carried out in the code ABAQUS [29] that (i) adopt member discretisations into fine 4-node isoparametric shell element meshes (length-to-width ratio roughly equal to 1) and (ii) model the fixed-ended support conditions by attaching rigid plates to the column end cross-sections, which are then only allowed to exhibit longitudinal rigid-body motions - a detailed account of all the modelling issues can be found in [9, 30]. The second part of the paper addresses the experimental investigation currently under way at COPPE (Federal University of Rio de Janeiro) and which will be fully reported in the near future - after providing a brief description of the test program, set-up and procedure, one compares the experimental results and numerical simulations concerning just one of specimens tested. Finally, several numerical ultimate strength values, as well as the whole set of available experimental collapse loads, are used to assess the applicability of the current Direct Strength Method (DSM) expressions to estimate the load-carrying capacity of cold-formed steel lipped channel columns experiencing $\mathrm{L} / \mathrm{D} / \mathrm{G}$ mode interaction - although further numerical and experimental studies are certainly needed, it is still possible to present some preliminary design considerations on the basis of the limited available data.

\section{BUCKLING BEHAVIOUR - COLUMN GEOMETRY SELECTION}

A sequence of buckling analyses (trial-and-error procedure) made it possible to identify a lipped channel column geometry (cross-section dimensions and length) ensuring almost coincident local, distortional and global buckling loads - these dimensions are: $b_{w}=75 \mathrm{~mm}$ (web height), $b_{f}=65 \mathrm{~mm}$ (flange width), $b_{l}=11 \mathrm{~mm}$ (lip width), $t=1.1 \mathrm{~mm}$ (wall thickness) and $L=235 \mathrm{~cm}$ (length). The curve depicted in Figure 2(a) concerns columns with these cross-section dimensions and provides the variation of the critical buckling load $P_{c r}$ with 
the length $L$ (logarithmic scale). As for Figure 2(b), it shows the shapes of the (coincident) $L=235 \mathrm{~cm}$ column local, distortional and flexural-torsional buckling modes. The observation of these ABAQUS buckling results prompts the following remarks:

(i) The $P_{c r}$ vs. $L$ curve exhibits three distinct zones, corresponding to $\left(\mathrm{i}_{1}\right)$ local buckling $(L<120 \mathrm{~cm}),\left(\mathrm{i}_{2}\right)$ local/distortional "mixed” buckling modes (almost horizontal plateau associated with extremely close buckling loads linked to local/distortional modes with various half-wave numbers) $(120<L<235 \mathrm{~cm})$, and $\left(i_{3}\right)$ global (flexural-torsional) buckling $(L>235 \mathrm{~cm})$.

(ii) Figure 2(a) clearly shows that the $L=235 \mathrm{~cm}$ column has very close $\mathrm{L}, \mathrm{D}$ and $\mathrm{G}$ critical loads, which indicates that the post-buckling behaviour and ultimate strength of such column will be highly affected by local/distortional/global interaction $\left(L=L_{L / D / G}\right)$. The critical buckling loads are $P_{c r . D 4}=55.9 \mathrm{kN}$ (4 distortional half-waves), $P_{c r . D 5}=56.8 \mathrm{kN}$ (5 distortional half-waves), $P_{c r . G}=57.1 \mathrm{kN}$ (single flexural-torsional half-wave) and $P_{c r . L}=57.4 \mathrm{kN}$ (33 web-triggered local half-waves ${ }^{1}$ - the corresponding buckling mode shapes are depicted in Figure 2(b).

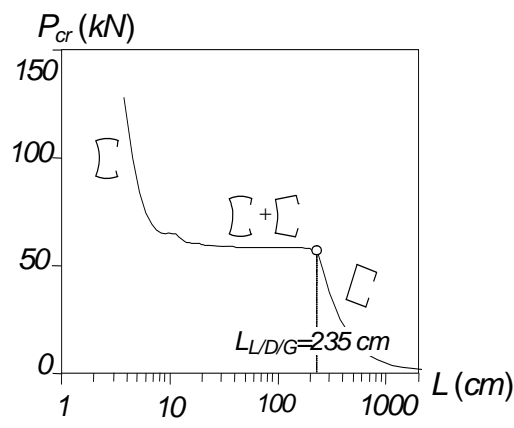

(a)

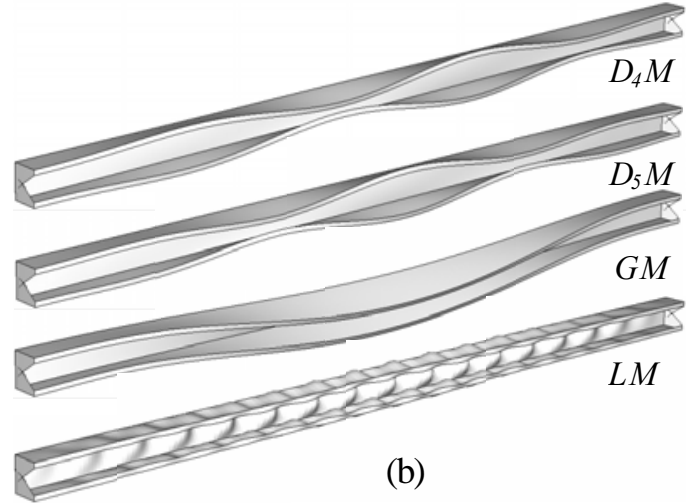

(b)

Figure 2. (a) Column $P_{c r}$ vs. $L$ Curve $\left(b_{w}=75 \mathrm{~mm} ; b_{f}=65 \mathrm{~mm} ; b_{l}=11 \mathrm{~mm} ; t=1.1 \mathrm{~mm}\right)$ and (b) $L_{L / D / G}=235 \mathrm{~cm}$ Column Local, Distortional and Global (Flexural-torsional) Buckling Mode Shapes

\section{POST-BUCKLING BEHAVIOUR UNDER L/D/G MODE INTERACTION}

One now investigates the elastic and elastic-plastic post-buckling behaviour of fixed-ended columns with the geometry identified in the previous section - recall that its critical buckling load is equal to $P_{c r}=55.9 \mathrm{kN}$ $\left(\sigma_{c r}=190.4 \mathrm{MPa}\right)$ and it exhibits almost coincident local (33 half-waves), distortional (4-5 half-waves) and global (single half-wave) buckling modes.

\subsection{Initial Geometrical Imperfections}

Because in mode interaction studies the commonly used approach of considering critical-mode initial geometrical imperfections ceases to be well defined, due to the presence of more than one competing buckling modes that may be combined arbitrarily, an important issue consists of assessing how the initial geometrical imperfection shape influences the post-buckling behaviour and strength of the structural system under scrutiny - in particular, it is crucial to identify the most detrimental imperfection shape. In order to achieve this goal, one determines column equilibrium paths covering the whole critical-mode imperfection shape range - to ensure that such paths can be meaningfully compared, the following approach is adopted:

\footnotetext{
${ }^{1}$ In fixed-ended lipped channel columns, the distortional buckling loads associated with buckling modes exhibiting consecutive half-wave numbers are always very close - this is why two distortional buckling modes must be considered in this work.
} 
(i) Determine the "pure" critical buckling mode shapes, normalised so that the most relevant displacement has a unit value. Such displacement is $\left(\mathrm{i}_{1}\right)$ the mid-span mid-web flexural displacement $\left(w_{L}=1 \mathrm{~mm}-\right.$ local), ( $\left.\mathrm{i}_{2}\right)$ the quarter-span flange-lip corner vertical displacement $\left(v_{D}=1 \mathrm{~mm}-\right.$ distortional $\left.^{2}\right)$ or $\left(\mathrm{i}_{3}\right)$ the mid-span flange-lip corner vertical displacement ${ }^{3}\left(v_{G}=1 \mathrm{~mm}\right.$ - global).

(ii) Scale down the above "pure" modes, leading to local, distortional and global imperfection magnitudes equal to $w_{L .0}=0.1 t, v_{D .0}=0.1 t$ and $v_{G .0}=L / 1000$.

(iii) A given imperfection shape is obtained as a linear combination of the scaled competing buckling mode shapes - its coefficients $C_{L .0}, C_{D .0}$ and $C_{G .0}$ satisfy the condition $\left(C_{L .0}\right)^{2}+\left(C_{D .0}\right)^{2}+\left(C_{G .0}\right)^{2}=1$. A better "feel" and visualisation of the initial imperfection shapes may be obtained by looking at an unit radius sphere drawn in the $C_{L .0}-C_{D .0}-C_{G .0}$ space, as shown in Figure 3(a): each "acceptable" shape lies on this sphere and can be defined by two angles ( $\alpha$ and $\theta$ ). Figures 3(b) display the pure $\mathrm{D}_{4}\left(\alpha=0^{\circ}+\theta=0^{\circ}\right.$ or $180^{\circ}$ - inward or outward flange-lip motions at quarter-span), $\mathrm{G}$ $\left(\alpha=0^{\circ}+\theta=90^{\circ}\right.$ or $270^{\circ}$ - clockwise or counter-clockwise cross-section rotations) and L $\left(\theta=0^{\circ}+\right.$ $\alpha=90^{\circ}$ or $270^{\circ}$ - inward or outward web bending at mid-span) initial imperfection shapes.

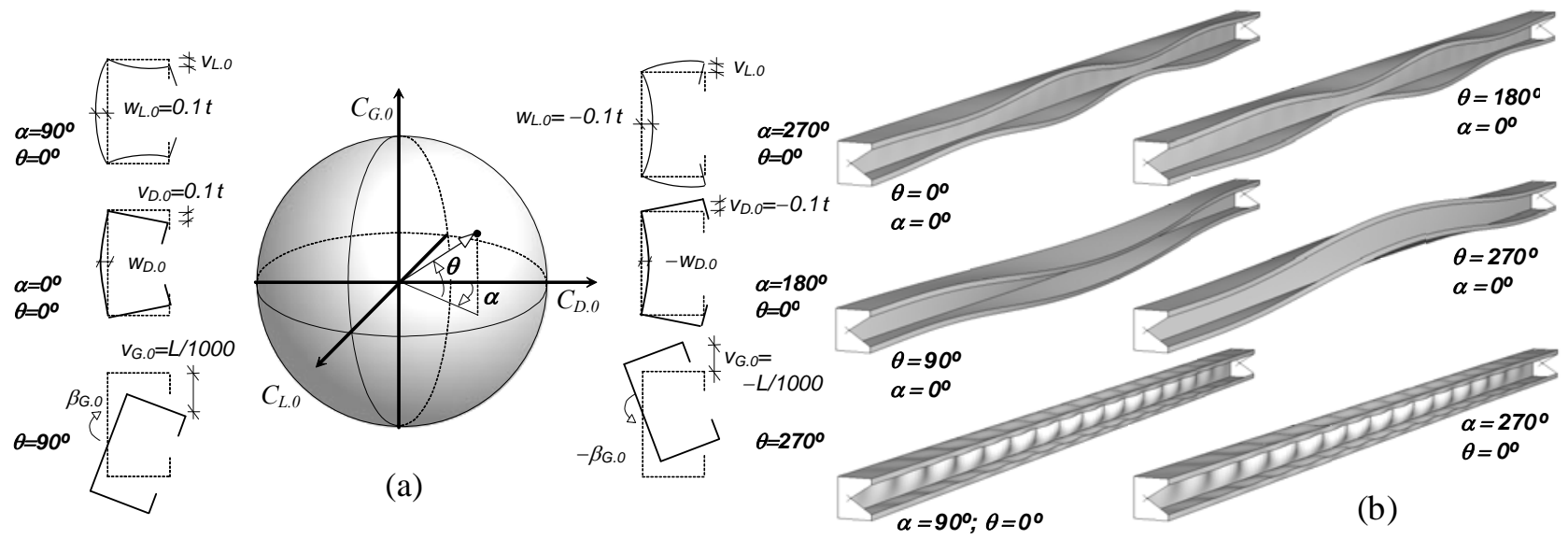

Figure 3. (a) Initial Imperfection Representation in the $C_{L .0}-C_{D .0}-C_{G .0}$ Space and

(b) Pure Distortional $\left(\alpha=0^{\circ}+\theta=0^{\circ} ; 180^{\circ}\right)$, Global $\left(\alpha=0^{\circ}+\theta=90^{\circ} ; 270^{\circ}\right)$ and Local $\left(\theta=0^{\circ}+\alpha=90^{\circ} ; 270^{\circ}\right)$ Initial Imperfection Shapes

\subsection{Elastic Post-Buckling Behaviour}

In order to investigate the elastic post-buckling behaviour of the $L_{L / D / G}$ column, a large number of otherwise identical columns with distinct initial imperfection shapes were analysed. However, due to space limitations, only some of the corresponding numerical results are presented here, adopting the following strategy: (i) presentation of the results concerning columns with the 6 pure critical initial imperfections shown in Figure 3(b), simply designated as $\theta=0^{\circ} ; 180^{\circ}$ (pure $\mathrm{D}_{4}$ distortional), $\theta=90^{\circ} ; 270^{\circ}$ (pure global) and $\alpha=90^{\circ} ; 270^{\circ}$ (pure local) columns; (ii) after observing the previous post-buckling results, identification of the two most detrimental imperfection shape types (i.e., those leading to larger erosions of the column elastic post-buckling strength reserve), which define the "most detrimental imperfection plane"; (iii) presentation of results concerning 24 columns with different initial imperfection shapes lying on the above plane (with $15^{\circ}$ angle intervals).

\footnotetext{
${ }^{2}$ No five half-wave distortional initial geometrical imperfections are dealt with here (only four half-wave ones). There are four and five half-wave distortional buckling modes associated with $P_{c r . D 4}=55.9 \mathrm{kN}$ (the lower value) and $P_{c r . D 5}=56.8 \mathrm{kN}$.

3 This vertical displacement is due to the cross-section rigid-body motion: rotation and a minor-axis translation - since both cause upward or downward vertical displacements, it suffices to define the cross-section rotation sense (clock or counterclockwise).
} 
Figures 4(a)-(c) show the upper parts of the equilibrium paths (i) $P / P_{c r} v s . v / t$ ( $v$ is half the sum of the two flange-lip corner vertical displacements), (ii) $P / P_{c r} v s . w / t$ ( $w$ is the mid-web flexural displacement, measured with respect to the web chord and after deducting the component stemming from the distortional deformation) and (iii) $P / P_{c r} v s$. $\beta$ ( $\beta$ is the web chord rigid-body rotation). It should be noted that $v, w$ and $\beta$ (i) are measured at the quarter-span section indicated in Figure 4(d) (S-S' cross-section), where maximum distortional deformations occurs, and (ii) are well suited to quantify the evolution of the column distortional, local and global deformed configuration components along any given equilibrium path. As for Figures 4(d), they show the deformed configurations of the $\theta=0^{\circ}, 180^{\circ}$ and $\alpha=90^{\circ}$ columns at the advanced post-buckling stage. From the observation of these post-buckling results, the following conclusions are drawn:

(i) All columns exhibit a stable post-buckling behaviour with a small-to-moderate post-critical strength reserve (see the various $P / P_{c r} v s . v / t$ and $P / P_{c r} v s . w / t$ curves displayed). This is somewhat surprising, since a previous study $[22,25]$ on simply supported columns experiencing strong $L / D / G$ mode interaction unveiled the existence of well defined limit points occurring quite below $P / P_{c r}=1.0$.

(ii) Generalised Beam Theory (GBT - e.g. Camotim, et al. [31]) provides the explanation for the distinct post-buckling behaviour nature exhibited by the simply supported and the fixed-ended lipped channel columns. The buckling results depicted in Figure 5(a) provide the variation of the critical buckling load $P_{c r}$ with the column length $L$ (for $L \geq 200 \mathrm{~cm}$ ): (ii ${ }_{1}$ ) the curve yielded by ABAQUS analyses and already shown in Figure 2(a), and $\left(\mathrm{ii}_{2}\right)$ the values obtained from GBT analyses carried out in GBTUL [32, 33] and including 18 deformation modes (4 global +2 distortional +12 local). As for Figure 5(b), it shows the GBT-based modal participation diagram, showing the contributions of each GBT deformation mode to the column buckling modes. Finally, Figures 5(c) display the GBT-based buckling mode shapes of the $L=300,500,700 \mathrm{~cm}$ columns and also the in-plane configurations of the 3 deformation modes that contribute to them. These GBT-based buckling results lead to the following comments:

(ii.1) The buckling curve descending branch corresponds to two distinct single half-wave buckling modes: (ii $\left.{ }_{1}\right)$ distortional-flexural-torsional $\mathbf{( 2 + 4 + 6 )}$, for $235<L \leq 500 \mathrm{~cm}$, and $\left(\mathrm{ii}_{2}\right)$ flexural-torsional $(2+4)$, for $L>500 \mathrm{~cm}$ - the participation of mode 6 (anti-symmetric distortional) gradually fades as the column length increases, until it practically vanishes for $L \approx 500 \mathrm{~cm}$.

(ii.2) This means that the $L=235 \mathrm{~cm}$ column single half-wave critical buckling mode, termed "global" until now, is indeed a "mixed" flexural-torsional-distortional mode, which combines about $35 \%$ of mode $2,40 \%$ of mode $\mathbf{4}$ and $25 \%$ of mode $\mathbf{6}$. The same happened in the simply supported column affected by L/D/G interaction analysed in [22, 25], where it was shown that the presence of mode $\mathbf{6}$ was responsible for the occurrence of (elastic) limit points. But why are there no such limit points in the fixed-ended column equilibrium paths?

(ii.3) Although a fully rational answer to the above question requires further investigation, which is currently under way and will be reported in the near future, it seems fair to anticipate that the explanation for the absence of elastic equilibrium path limit points has to do with both ( $\mathrm{ii}_{1}$ ) the smaller contribution of mode $\mathbf{6}$ (it reached $32 \%$ in the simply supported columns analysed in [22, 25]) and ( $\mathrm{ii}_{2}$ ) the absence of a destabilising effective centroid shift associated with this anti-symmetric distortional deformation mode (e.g., Young and Rasmussen [34]).

(iii) The columns with "global" (this designation will be retained for simplicity) initial imperfections $\left(\theta=90^{\circ}\right.$ or $270^{\circ}$ ) exhibit deformed configurations characterised by quarter-span (iii 1 ) small outward flange-lip motions, ( $\left.\mathrm{iii}_{2}\right)$ moderate inward or outward web bending and (iii ${ }_{3}$ ) significant clockwise or counterclockwise rigid-body rotations - the presence of non-null distortional and local (mostly) components indicates $\mathrm{L} / \mathrm{D} / \mathrm{G}$ interaction.

(iv) The small $v$ values exhibited by some equilibrium paths do not correspond to minute distortional deformations. Indeed, they are due to the simultaneous presence of four $\left(D_{4}\right)$ and five $\left(D_{5}\right)$ half-wave distortional components, whose interaction leads to small $v$ values at the quarter-span 
(S-S') cross-section - therefore, this cross-section is not the most convenient to characterise the $\mathrm{L} / \mathrm{D} / \mathrm{G}$ interaction.

(v) The columns with distortional $\left(\theta=0^{\circ}, 180^{\circ}\right)$ or local $\left(\alpha=90^{\circ}, 270^{\circ}\right)$ initial imperfections have deformed configurations with no rigid-body rotations, i.e., only L/D interaction occurs (see Figure 4(d)).

(vi) Because the local $\left(\alpha=90^{\circ}, 270^{\circ}\right)$ initial imperfections always lead to higher column elastic post-buckling strengths than their global and distortional counterparts, one readily concludes that the most adverse $\mathrm{L} / \mathrm{D} / \mathrm{G}$ interaction effects occur for initial imperfections lying in the $\mathrm{C}_{\mathrm{D}}-\mathrm{C}_{\mathrm{G}}$ plane. Note that this conclusion is in line with the findings reported earlier for simply supported columns [22, 25]: the initial imperfection local component plays a lesser role, as far as the post-buckling behaviour of columns experiencing $L / D / G$ interaction is concerned [16].

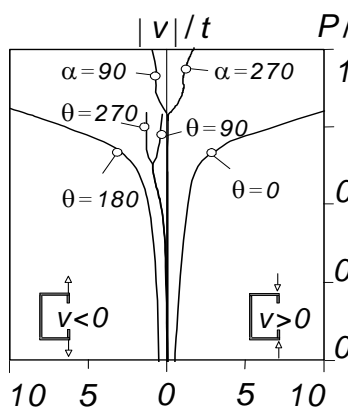

(a)

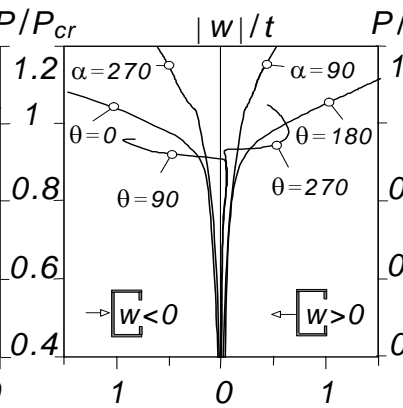

(b)

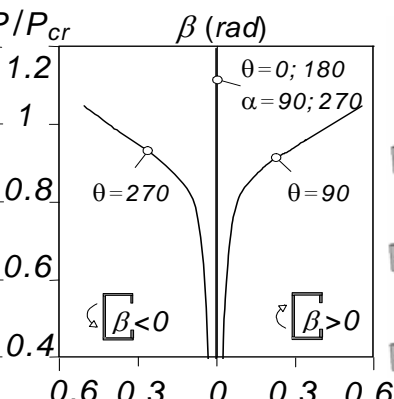

(c)

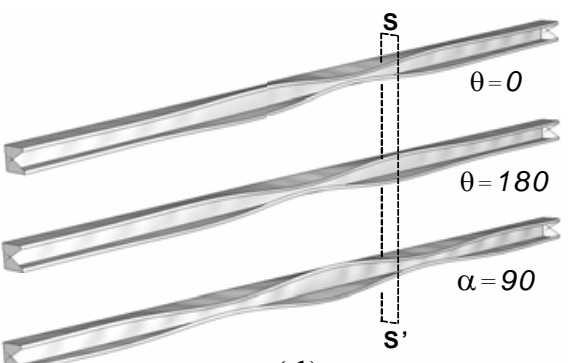

(d)

Figure 4. (a) $P / P_{c r} v s . v / t$, (b) $P / P_{c r} v s . w / t$ and (c) $P / P_{c r} v s . \beta$ Paths for Columns with Pure Imperfections Shapes; (d) Advanced Post-buckling Deformed Configurations of the $\theta=0^{\circ}, \theta=180^{\circ}$ and $\alpha=90^{\circ}$ Columns

(a)

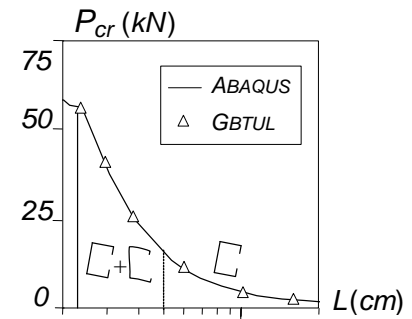

(b)

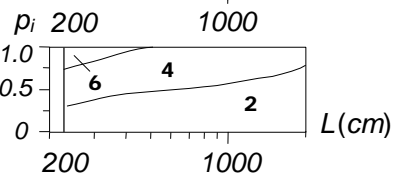

\begin{tabular}{|c|c|c|c|}
\hline$L(\mathrm{~cm})$ & 300 & 500 & 700 \\
\hline $\begin{array}{c}\text { GBT } \\
\text { Buckling } \\
\text { Mode }\end{array}$ & $\square$ & $\square$ & $\square$ \\
\hline
\end{tabular}

(c)

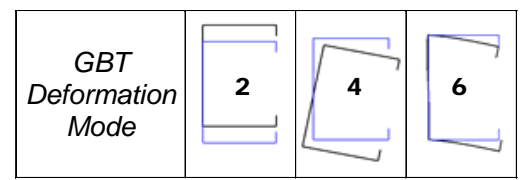

Figure 5. (a) GBT-based $P_{c r}$ values $(L>200 \mathrm{~cm})$, (b) Modal Participation Diagram and (c) In-plane Shapes of the $L=300,500,700 \mathrm{~cm}$ Column Buckling Modes and Participating GBT Deformations Modes

In view of the above facts, attention is now focused on the post-buckling behaviour of columns with 13 initial imperfections located in the $\mathrm{C}_{\mathrm{D}}-\mathrm{C}_{\mathrm{G}}$ plane and corresponding to $0^{\circ}<\theta<180^{\circ}\left(15^{\circ}\right.$ intervals - to ensure $C_{G} \neq 0$, the $\theta=0^{\circ}$ and $180^{\circ}$ columns are replaced by $\theta=1^{\circ}$ and $179^{\circ}$ ones $)^{4}$. Figures 6(a)-(c) show the upper parts of the $P / P_{c r} v s . v / t, P / P_{c r} v s$. $w / t$ and $P / P_{c r} v s . \beta$ equilibrium paths, which now concern mid-span cross-section displacements - due to the relevant presence of $\mathrm{D}_{5}$ distortional deformations (they always come into play, even if only $\mathrm{D}_{4}$ initial imperfections are included in the analysis), this cross-section is more adequate to characterise the $\mathrm{L} / \mathrm{D} / \mathrm{G}$ interaction.

\footnotetext{
${ }^{4}$ Since the column post-buckling behaviour was found to be symmetric with respect to the deformed configuration global component sign (see Fig. 4(c)), there is no need to present post-buckling results concerning the $180^{\circ}<\theta<360^{\circ}$ columns.
} 
Figure 6(d) shows the deformed configurations of the $\left(\mathrm{d}_{1}\right) \theta=1^{\circ}$ column (at the peak load) and $\left(\mathrm{d}_{2}\right) \theta=90^{\circ}$ column (at advanced post-buckling stage). In order to illustrate some behavioural aspects detected in the above equilibrium paths and not visible in Figures 6(a)-(b), additional results are presented in Figures 7(a)-(c): more detailed representations of the $\theta=90^{\circ}$ curves displayed in Figures 6(a)-(b), together with several column mid-span cross-section deformed configurations. The joint observation of all these post-buckling results prompts the following remarks:

(i) All equilibrium paths shown in Figures 6(a)-(c) merge into single common curves, associated with mid-span $\left(i_{1}\right)$ clockwise web chord rotations, $\left(i_{2}\right)$ outward flange-lip motions and $\left(i_{3}\right)$ outward web bending (i.e., opposing the web bending caused by the distortional component) - this provides clear evidence of strong $\mathrm{L} / \mathrm{D} / \mathrm{G}$ interaction. Moreover, note that, since the column deformed configuration $\mathrm{D}_{5}$ distortional component has always the same sign (outward flange-lip motions at mid-span), the column post-buckling behaviour is symmetric with respect to $\theta=90^{\circ}$.

(ii) The progressive emergence of significant distortional deformations at the column mid-span cross-section means that the $\mathrm{L} / \mathrm{D} / \mathrm{G}$ interaction involves also (or mostly) the non-critical 5 half-wave distortional buckling mode $\left(\mathrm{D}_{5}\right)$. In spite of its slightly higher buckling load, this distortional mode is geometrically more akin to the global and local ones (maximum displacements at mid-span) and plays a key role in the column post-buckling behaviour, as can be seen in Figure $6\left(\mathrm{~d}_{2}\right)$ - note also the visibility of the column deformed configuration local component (barely perceptible in the simply supported columns analysed in [22, 25]).

(iii) The equilibrium paths of the columns with a very small $C_{G .0}$ value $\left(\theta=1^{\circ} ; 179^{\circ}\right)$ lie clearly above the remaining ones and reach a limit point prior to merging into the common curve - this is due to (iii ${ }_{1}$ ) the decrease of their "excessive” $\mathrm{D}_{4}$ components (see Figure 6( $\left.\mathrm{d}_{1}\right)$ ) and (iii ${ }_{2}$ ) the very close proximity of the singular post-buckling behaviour of the $\theta=0^{\circ} ; 180^{\circ}$ columns, which involves no cross-section rigid-body motions [22, 25]. As for the other equilibrium paths, they are all "smooth" (particularly those concerning columns with small $C_{D .0}$ values) and evolve in a monotonic fashion.

(iv) The most detrimental initial imperfections, in the sense that they lead to the lowest column post-buckling strength, are the pure "global" ones $\left(\theta=90^{\circ}\right)$ - indeed, the corresponding equilibrium paths shown in Figures 6(a)-(c) lie below all the remaining ones.

(v) In the advanced post-buckling stages $\left(P / P_{c r}>0.93\right.$ and $\left.v / t>5\right)$, a gradual change occurs in the column common deformed configuration - this change is clearly visible in the $\theta=90^{\circ}$ column equilibrium paths depicted in Figures 7(a)-(b). First of all, the rate of increase of the outward web bending displacements $(w)$, measured with respect to the web chord and deducting the distortional component, progressively diminishes, until a "reversal" takes place (i.e., the web deformed configuration local component corresponds now to inward bending) - note also the emergence of a visible web double-curvature bending, stemming from the growth of the deformed configuration "global" component. Secondly, the rate of increase of the flange-lip distortional displacements (v) decreases, until another "reversal" takes place (i.e., the flange-lip assemblies start to move inward) this means that while the mid-span cross-section rigid-body rotation and associated anti-symmetric distortion keep growing (see Figure 7(c)), its symmetric distortion slowly starts to decease.

\subsection{Elastic-Plastic Post-Buckling Behaviour}

Numerical results concerning the elastic/perfectly-plastic post-buckling behaviour and collapse mechanism of the $\mathrm{L} / \mathrm{D} / \mathrm{G}$ column are now presented and discussed. Again due to space limitations, only the most relevant results are dealt with: those that correspond to columns with (i) initial imperfection shapes lying in the $\mathrm{C}_{\mathrm{D}}-\mathrm{C}_{\mathrm{G}}$ plane $\left(1^{\circ}<\theta<179^{\circ}-15^{\circ}\right.$ intervals), and (ii) yield stresses $f_{y}=235,355,520$ $M P a$, i.e., yield-to-critical stress ratios equal to $f_{y} / \sigma_{c r} \approx 1.2,1.9,2.7$. For comparative purposes, some elastic results presented earlier are shown again - they may be viewed as corresponding to $f_{y}=f_{y} / \sigma_{c r}=\infty$. 


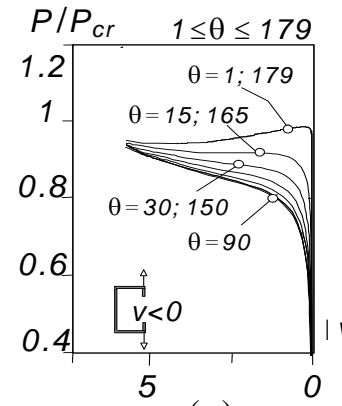

(a)

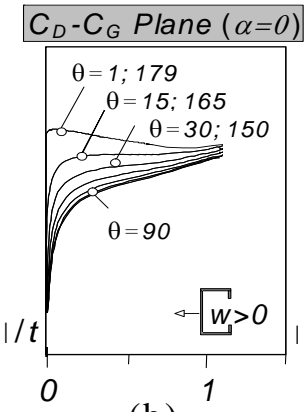

(b)

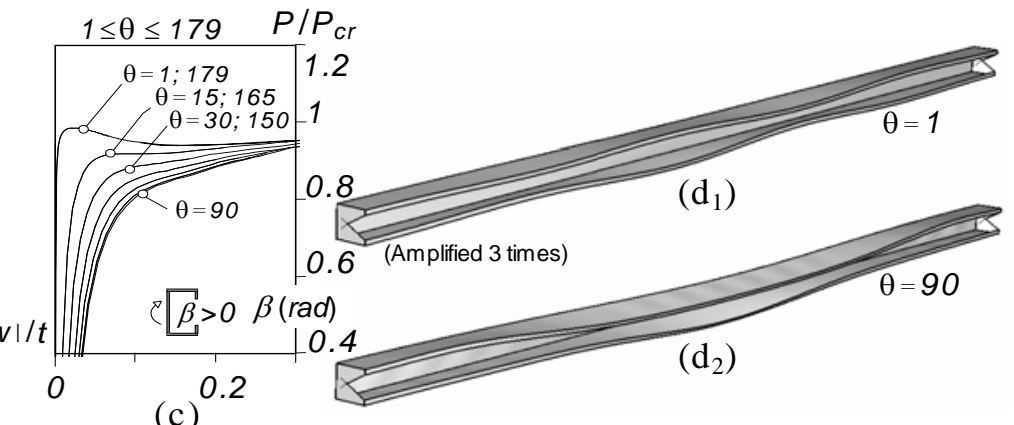

(c)

Figure 6. (a) $P / P_{c r} v s . v / t$, (b) $P / P_{c r} v s . w / t$ and (c) $P / P_{c r} v s . \beta$ Paths for $\mathrm{C}_{\mathrm{D}}-\mathrm{C}_{\mathrm{G}}$ Plane Imperfections, and (d) Deformed Configuration of the $\left(\mathrm{d}_{1}\right)$ the $\theta=1^{\circ}$ (Peak Load) and

$\left(\mathrm{d}_{2}\right)$ the $\theta=90^{\circ}$ (Advanced Post-buckling Stage) Columns

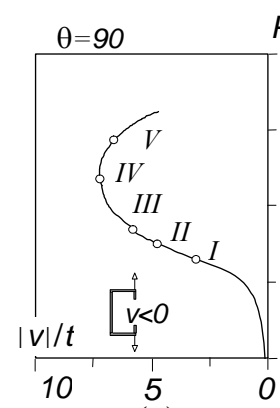

(a)

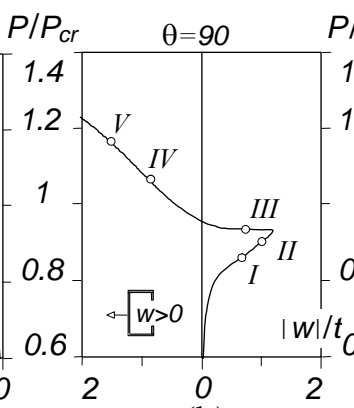

(b)

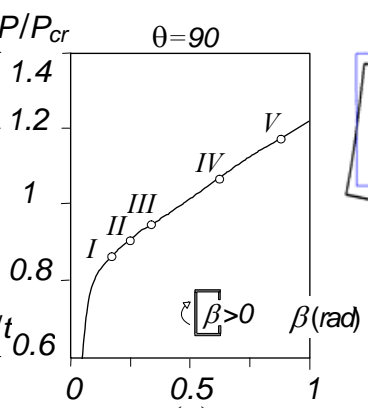

(c)

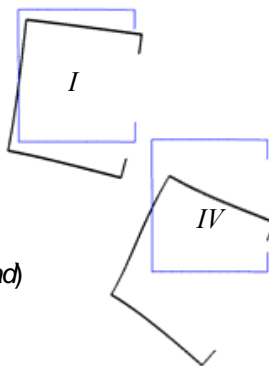

(d)

Figure 7. (a) $P / P_{c r} v s . v / t$, (b) $P / P_{c r} v s . w / t$, and (c) $P / P_{c r} v s . \beta$ Equilibrium Paths, and (c) Post-buckling Evolution of the $\theta=90^{\circ}$ Column Mid-span Cross-section Deformed Configuration

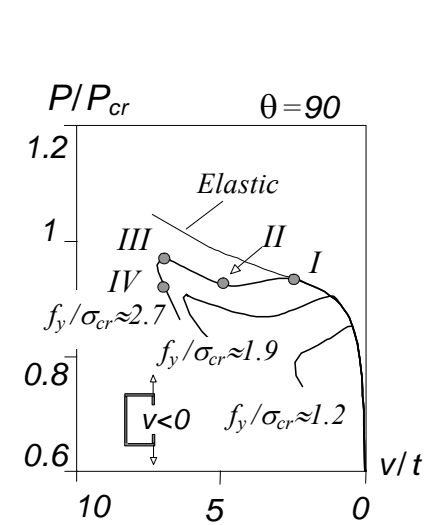

(a)

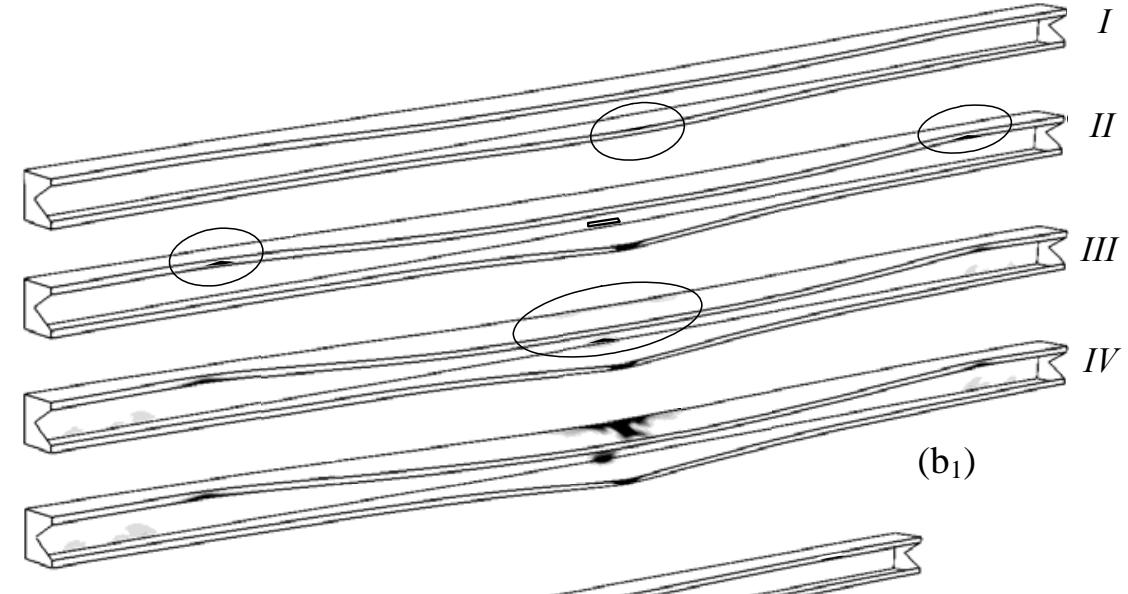

$\left(b_{2}\right)$

Figure 8. (a) Elastic-Plastic $P / P_{c r} v$ s. $v / t$ Equilibrium Paths of Four $\theta=90^{\circ}$ Columns $\left(f_{y} / \sigma_{c r} \approx 1.2,1.9\right.$, $2.7, \infty)$ and (b) Deformed Configuration and Plastic Strain Diagrams of the $\theta=90^{\circ}$ Column with $\left(\mathrm{b}_{1}\right) f_{y} / \sigma_{c r} \approx 2.7$ (Four Equilibrium States Indicated) and $\left(\mathrm{b}_{2}\right) f_{y} / \sigma_{c r} \approx 1.2$ (Onset of Yielding - Peak Load) 
Figure 8(a) shows the upper portions $\left(P / P_{c r}>0.0\right)$ of four equilibrium paths $P / P_{c r} v s . v / t$, concerning $\theta=90^{\circ}$ columns (most detrimental initial imperfections) with different yield stresses. Figure $8\left(\mathrm{~b}_{1}\right)$ concerns the column with $f_{y} / \sigma_{c r} \approx 2.7$ and displays four plastic strain diagrams, corresponding to equilibrium states located along its post-buckling path (as indicated in Figure 8(a)) and including the column collapse mechanism - in order to illustrate the influence of the yield stresses on the column collapse mechanism, Figure $8\left(\mathrm{~b}_{2}\right)$ displays the plastic strain diagrams at the collapse of the $\theta=90^{\circ}$ columns with $f_{y} / \sigma_{c r} \approx 1.2$. As for Figures 9(a)-(b), they show similar elastic-plastic results concerning $\theta=1^{\circ}$ columns (almost pure distortional initial imperfections). Finally, Figure 10 (and its table) provides the column ultimate load ratios $\left(P_{u} / P_{c r}\right)$ for all the $\theta-f_{y}$ combinations considered in this work. After observing these $1^{\circ} \leq \theta \leq 179^{\circ}$ column post-buckling results, one is able to draw the following conclusions:

(i) The characteristics of the column elastic-plastic post-buckling behaviour and collapse mechanism are clearly dependent on the $f_{y} / \sigma_{c r}$ value.

(ii) In columns with $f_{y} / \sigma_{c r}$ close to $1.0\left(e . g ., f_{y} / \sigma_{c r} \approx 1.2\right)$ first yielding occurs when the column normal stress distribution is still "fairly uniform" and, therefore, precipitates a rather "abrupt" collapse. The onset of yielding occurs in a significant portion of the "critical (most deformed) cross-section", whose location depends on the initial imperfection shape: (ii ${ }_{1}$ ) for $\theta=1^{o}$, the mid cross-section of the mode $\mathrm{D}_{4}$ inner half-wave with outward motions (see Figure $9\left(\mathrm{~b}_{2}\right)$ ), which means that yielding begins before mode $\mathrm{D}_{5}$ comes into play; ( $\left.\mathrm{ii}_{2}\right)$ for $\theta=90^{\circ}$, in the column mid-span, which implies that mode $\mathrm{D}_{5}$ has already become dominant (see Figure $8\left(\mathrm{~b}_{2}\right)$ ).

(iii) In columns with a high $f_{y} / \sigma_{c r}$ value (e.g., $f_{y} / \sigma_{c r} \approx 2.7$, the higher value considered here) first yielding occurs when the column normal stress distribution is already "strongly non-uniform" and, therefore, does not lead to an immediate collapse. Either (iii $\left.{ }_{1}\right)$ the column remains elastic up until failure, i.e., yielding only starts along the equilibrium path descending branch (e.g., the $\theta=1^{\circ}$ column - see Figure 9(a)), or ( $\mathrm{iii}_{2}$ ) collapse occurs after a mild "snap-through" phenomenon takes place, followed by a subsequent strength increase up to a limit point ${ }^{5}$ (e.g., the $\theta=90^{\circ}$ column - see Figure 8(a)).

(iv) For the $\theta=90^{\circ}$ column with $f_{y} / \sigma_{c r} \approx 2.7$, yielding begins at the bottom lip free end zone located in the vicinity of the column mid-span, as shown by the plastic strain distribution corresponding to the equilibrium state $I$ in Figure 8( $\left.\mathrm{b}_{1}\right)$. Then, the plastic strain distribution associated with the equilibrium point $I I$ indicates that yielding also begins at the top lip free end in the eighth-span cross-section zones. The column collapse, which corresponds to the equilibrium path (second) limit point, takes place after the full yielding of the mid-span cross-section web-flange corners, thus forming a "distortional plastic hinge" - see diagram $I I I$ in Figure 8( $\left.\mathrm{b}_{1}\right)$. Finally, diagram $I V$ corresponds to a post-collapse equilibrium state and shows that yielding spreads along the upper half of the mid-span cross-section region, while practically all the other column zones remain elastic.

(v) Figure 10 shows that the $\theta=90^{\circ}$ column always exhibits the lowest ultimate load, which means that pure "global" initial imperfections are the most detrimental ones. Concerning the strength erosion due to the $\mathrm{L} / \mathrm{D} / \mathrm{G}$ interaction, the $\theta=90^{\circ}$ column ultimate load is equal to $74 \%\left(f_{y}=235 \mathrm{MPa}\right), 81 \%$ $\left(f_{y}=355 \mathrm{MPa}\right)$ and $89 \%\left(f_{y}=520 \mathrm{MPa}\right)$ of its critical buckling load.

(vi) Figure 10 (and its table) also shows that the variation of $P_{u} / P_{c r}$ with $\theta$ is less pronounced as $f_{y} / \sigma_{c r}$ increases - this is due to the fact that the elastic equilibrium paths concerning the various $\theta$ values are closer to each other when yielding begins (recall that they eventually merge into a common curve). Note that the interval centred at $\theta=90^{\circ}$ for which $P_{u}$ is "almost uniform" (maximum and minimum values no more than $0.5 \%$ apart) grows from $75^{\circ} \leq \theta \leq 105^{\circ}\left(f_{y} / \sigma_{c r} \approx 1.2\right)$ to $15^{\circ} \leq \theta \leq$ $165^{\circ}\left(f_{y} / \sigma_{c r} \approx 2.7\right)$.

\footnotetext{
${ }^{5}$ It is worth noting that, as the $f_{y} / \sigma_{c r}$ ratio increases, the "snap-through" phenomenon becomes less pronounced and the subsequent strength increase is larger.
} 


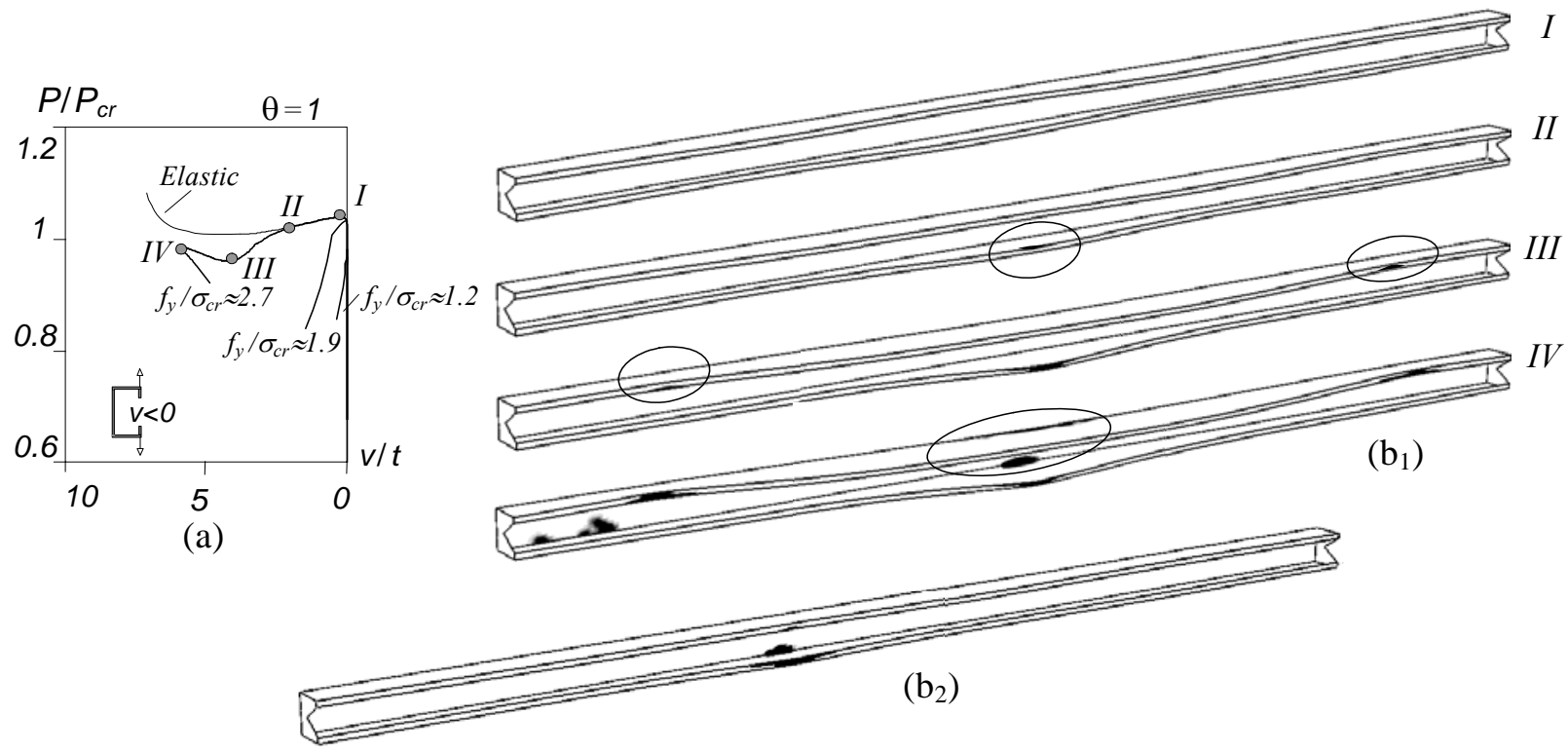

Figure 9. (a) Elastic-plastic $P / P_{c r} v s . v / t$ Equilibrium Paths of Four $\theta=1^{\circ}$ Columns $\left(f_{y} / \sigma_{c r} \approx 1.2,1.9,2.7, \infty\right)$, (b) Deformed Configuration and Plastic Strain Diagrams of the $\theta=1^{\circ}$ Columns with $\left(\mathrm{b}_{1}\right) f_{y} / \sigma_{c r} \approx 2.7$ (Four Equilibrium States Indicated) and $\left(\mathrm{b}_{2}\right) f_{y} / \sigma_{c r} \approx 1.2$ (Onset of Yielding - Peak Load)

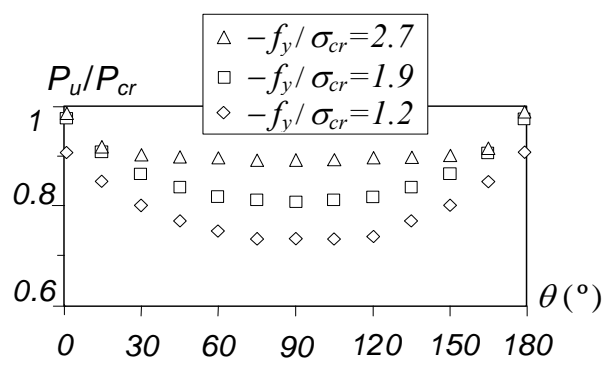

\begin{tabular}{|c|c|c|c|}
\hline \multirow{2}{*}{$\theta\left(^{\circ}\right)$} & \multicolumn{3}{|c|}{$f_{y} / \sigma_{c r}$} \\
\cline { 2 - 4 } & 1.2 & 1.9 & 2.7 \\
\hline 1 & 0.908 & 0.977 & 0.987 \\
15 & 0.851 & 0.908 & 0.919 \\
30 & 0.803 & 0.866 & 0.903 \\
45 & 0.772 & 0.840 & 0.898 \\
60 & 0.751 & 0.819 & 0.898 \\
75 & 0.736 & 0.814 & 0.894 \\
90 & 0.735 & 0.809 & 0.893 \\
\hline
\end{tabular}

\begin{tabular}{|c|c|c|c|}
\hline \multicolumn{4}{|c|}{$f_{y} / \sigma_{c r}$} \\
\hline$\theta\left(^{\circ}\right)$ & 1.2 & 1.9 & 2.7 \\
\hline 90 & 0.735 & 0.809 & 0.893 \\
105 & 0.736 & 0.814 & 0.894 \\
120 & 0.751 & 0.820 & 0.897 \\
135 & 0.771 & 0.841 & 0.899 \\
150 & 0.802 & 0.867 & 0.904 \\
165 & 0.850 & 0.909 & 0.920 \\
179 & 0.909 & 0.978 & 0.988 \\
\hline
\end{tabular}

Figure 10. Variation of $P_{u} / P_{c r}$ with $\theta$ and $f_{y} / \sigma_{c r}\left(1^{\circ} \leq \theta \leq 179^{\circ}\right)$

\section{EXPERIMENTAL INVESTIGATION}

This section addresses the experimental investigation currently under way at COPPE (Federal University of Rio de Janeiro) and will be fully reported in the near future - after providing a brief description of the test program, set-up and procedure, the paper compares the experimental results and numerical simulations concerning one of the specimens tested.

\subsection{Test Program, Set-Up, Procedure and Results}

In order to ensure the occurrence of strong local/distortional/global mode interaction, four fixed-ended column geometries with close local, distortional and global buckling loads were first selected - the experimental investigation involves 9 tests and the specimen dimensions are given in Table 1 (note that, due to fabrication limitations, the wall thickness is always close to $1.1 \mathrm{~mm}$ ), together with the corresponding (i) buckling loads, calculated for $E=210 \mathrm{GPa}$ and $v=0.3$, and (ii) measured ultimate loads. The specimens were cold-formed by press braking and their average yield stress values, obtained from coupon tests, is equal to $342 \mathrm{MPa}$ or $407 \mathrm{MPa}$ (4 tests and a $4.0 \mathrm{MPa}$ 
standard deviation), corresponding to the critical-to-yield load ratios also given in Table 1 ( $P_{y}=A f_{y}$ is the column squash load) - moreover, the coupon tests carried out showed that the steel stress-strain curve exhibited no well-defined yield plateau (see Figure 12(a)).

Figure 11(a) shows the location of the 7 displacement transducers employed to measure the specimens initial geometrical imperfections and displacements during the tests - Figure 11(b) shows a view of the specimen mid-span cross-section surrounded by transducers T3 to T6. In order to measure the specimen initial displacement longitudinal profiles, only transducers T1 to T6 were attached to the moving device, which was subsequently made to travel along the whole column length. Concerning the displacement measurements made during the test, the following methodology was employed:

(i) Transducers T2 to T5 and T7 were kept permanently at the mid-height level, in contact with the specimen by means long steel wires - this arrangement aims at ensuring contact with the specimen even when the cross-section rigid-body motion ceases to be small.

(ii) Transducers T1 and T6 were attached to the moving device, which was kept at the mid-height level during the application of the various load increments. At pre-defined applied load values, loading was stopped and the moving device travelled along the specimen length, thus providing the longitudinal profiles of the flange-lip corner vertical displacements for the load value under consideration.

(iii) During the application of the load increments, the measurements of the 7 transducers (all located at the mid-height level) were continuously recorded and fed into a data acquisition system.

Table 1. Geometries, Buckling Loads and Ultimate Strengths of the Columns Tested

\begin{tabular}{|c|c|c|c|c|c|c|c|c|c|c|c|}
\hline Specimen & $\begin{array}{c}b_{w} \\
(\mathrm{~mm})\end{array}$ & $\begin{array}{c}b_{f} \\
(\mathrm{~mm})\end{array}$ & $\begin{array}{c}b_{l} \\
(\mathrm{~mm})\end{array}$ & $\begin{array}{c}t \\
(\mathrm{~mm})\end{array}$ & $\begin{array}{c}L \\
(\mathrm{~mm})\end{array}$ & $\begin{array}{c}f_{y} \\
(\mathrm{MPa})\end{array}$ & $\begin{array}{c}P_{c r . L} \\
(\mathrm{kN})\end{array}$ & $\begin{array}{c}P_{c r . D} \\
(\mathrm{kN})\end{array}$ & $\begin{array}{c}P_{c r . F T} \\
(\mathrm{kN})\end{array}$ & $\begin{array}{c}P_{c r . D} \\
/ P_{y}\end{array}$ & $\begin{array}{c}P_{u} \\
(\mathrm{kN})\end{array}$ \\
\hline $\begin{array}{c}1 \\
2\end{array}$ & 81 & 72 & 12 & 1.07 & 2850 & 342 & 43.8 & 42.9 & 45.4 & 0.43 & $\begin{array}{c}31.5 \\
29.0 \\
3\end{array}$ \\
\hline $\begin{array}{c}4 \\
5\end{array}$ & 75 & 65 & 11 & 1.07 & 2350 & 342 & 48.8 & 47.5 & 49.6 & 0.55 & $\begin{array}{c}33.0 \\
31.2\end{array}$ \\
\hline 6 & 71 & 60 & 11 & 1.07 & 2100 & 342 & 51.9 & 51.8 & 52.9 & 0.64 & $\begin{array}{c}35.1 \\
34.0\end{array}$ \\
\hline 7 & 76 & 60 & 10 & 1.11 & 2350 & 407 & 49.0 & 47.7 & 47.5 & 0.49 & $\begin{array}{c}36.5 \\
34.1\end{array}$ \\
\hline 9
\end{tabular}

(a)

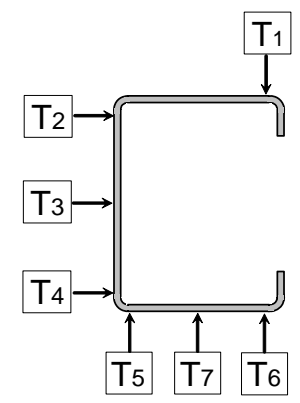

(b)

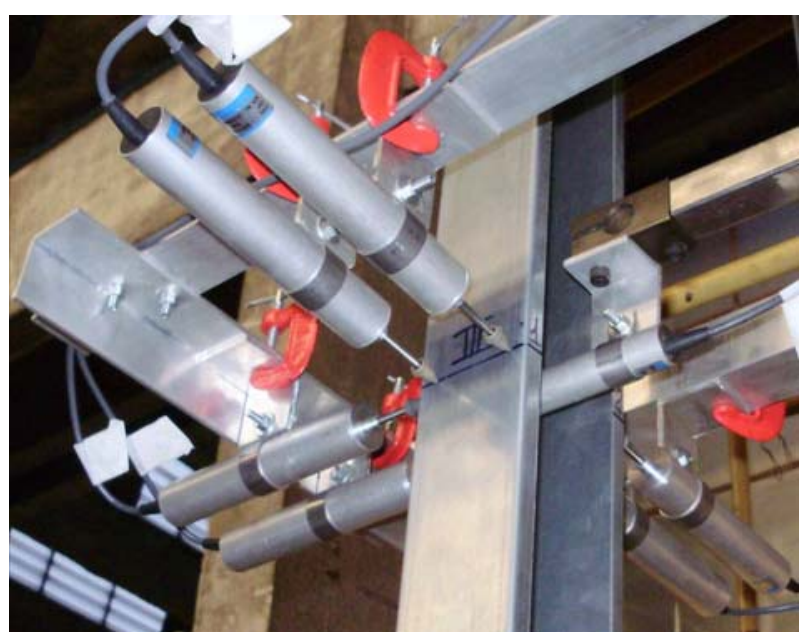

Figure 11. (a) Displacement Transducer Cross-section Locations and (b) View of the Moving Device used to Obtain the Longitudinal Profiles of Some Measured Displacements 


\subsection{Comparison between Numerical and Experimental Results}

The comparison between numerical and experimental results concerns just one test carried out at COPPE the specimen has mid-line dimensions $b_{w}=76 \mathrm{~mm}, b_{f}=64 \mathrm{~mm}, b_{l}=11 \mathrm{~mm}, t=1.07 \mathrm{~mm}$ and $L=235.2 \mathrm{~cm}$ (specimen 4), i.e., very similar to those considered in the numerical investigation reported earlier. The ABAQUS shell finite element numerical simulations performed exhibit the following characteristics:

(i) The steel is deemed homogeneous and isotropic, with an elastic-plastic behaviour described by a multi-linear model that $\left(\mathrm{i}_{1}\right)$ assumes $E=211 \mathrm{GPa}, v=0.3$ and $f_{y}=342 \mathrm{MPa}$ (coupon test average values) and $\left(\mathrm{i}_{2}\right)$ approximates the measured stress-strain curve, prior to the yield plateau, by linear segments connecting the experimental curve points concerning four stress values $\left(\sigma=0.55 f_{y}\right.$, $0.80 f_{y}, 0.93 f_{y}$ and $f_{y}$ ) - Figure 12(a) presents a comparison between the experimental stress-strain curve and the multi-linear one adopted to model it in the numerical simulations.

(ii) The column end sections are fixed: with the sole exception of the rigid-body longitudinal displacement of the loaded end section, which is free, all the displacements and rotations are fully prevented.

(iii) Both the residual stresses (not measured in the tested specimens) and corner effects are neglected.

(iv) The initial geometrical imperfections model those measured in the tested specimen - they are obtained by means of the procedure illustrated in Figure 12(b) and described next. For each of the 6 cross-section displacements measured along the specimen length (transducers T1 to T6 - see Figure 11(a)), the Fourier transform approach is used to obtain a linear combination of trigonometric functions that approximates the experimental values - Figure 12(b) shows a comparison between the experimental and numerical initial values of the horizontal displacements $d_{4}$ occurring along the bottom web-flange longitudinal edge (measured by transducer T4). The 6 initial displacement approximation functions are then incorporated into the shell finite element mesh - whenever necessary, a linear displacement variation along the cross-section wall mid-line is assumed between the equally spaced web, flange or lip nodes.

Figure 13(a) show the comparison between the equilibrium paths $P v s . d_{1}$ and $P v s . d_{6}$, where $d_{1}$ and $d_{6}$ are the mid-span vertical displacements of the flange-lip corners (positive upward) (see Figure 11(a)), (i) obtained during the test carried out at COPPE and (ii) provided by the ABAQUS analysis the table below provides the experimental $\left(P_{u . E}\right)$ and numerical $\left(P_{u . N}\right)$ ultimate load values. As for Figure 13(b), it shows numerical and experimental representations of the column failure mode. The observation of these results prompts the following remarks:

(i) The numerical post-buckling equilibrium paths follow fairly closely their experimental counterparts (note, in particular, that the $d_{l}$ numerical curve practically coincides with the experimental one) and exhibit very similar peak loads $-P_{u . E}$ is only $0.3 \%$ above $P_{u . N}$. Moreover, they provide clear evidence of distortional/global interaction - indeed, they concern ( $\mathrm{i}_{1}$ ) counter-clockwise rigid-body rotations (both $d_{1}$ and $d_{6}$ are positive, i.e., upward) and (i $\left.\mathrm{i}_{2}\right)$ outward motions of the flange-lip assemblies $\left(d_{1}\right.$ is larger than $\left.d_{6}\right)$ at the mid-span cross-section.

(ii) However, there are some differences between the experimental and numerical curves, as the latter exhibits ( $\mathrm{ii}_{1}$ ) a considerably higher ductility (displacements at collapse about twice those measured in the test) and ( $\mathrm{ii}_{2}$ ) a very small (almost imperceptible) snap-through phenomenon - note that this phenomenon is much less pronounced than that depicted in Figure 8(a), which is probably due to the different stress-strain curves adopted to model the steel material behaviour (linear and multi-linear).

(iii) As shown in Figure 13(b), there is a quite satisfactory match between the ABAQUs failure mode and the collapse mechanism observed during the test: both are almost symmetric and provide evidence of distortional/global interaction. Note, however, that local deformations are not perceptible in either of them (recall that they were clearly visible in the elastic post-buckling advanced stages - see Figure $\left.6\left(d_{2}\right)\right)$ 
(a)

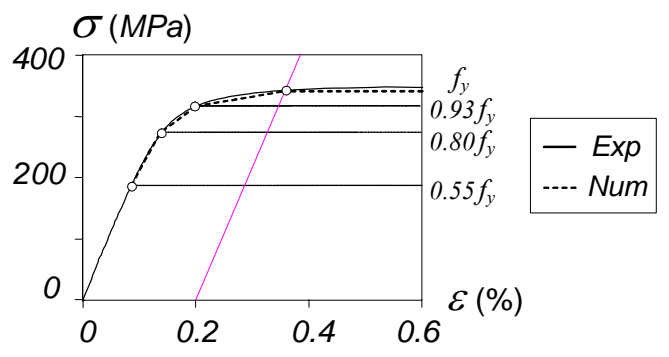

(b)

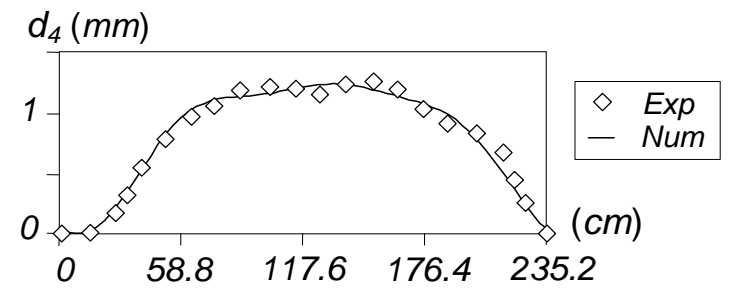

Figure 12. Comparison between the Experimentally Obtained and Numerically Modelled

(a) Stress-strain Curve and (b) $d_{4}$ Displacement Values along the Bottom Web-flange Longitudinal Edge

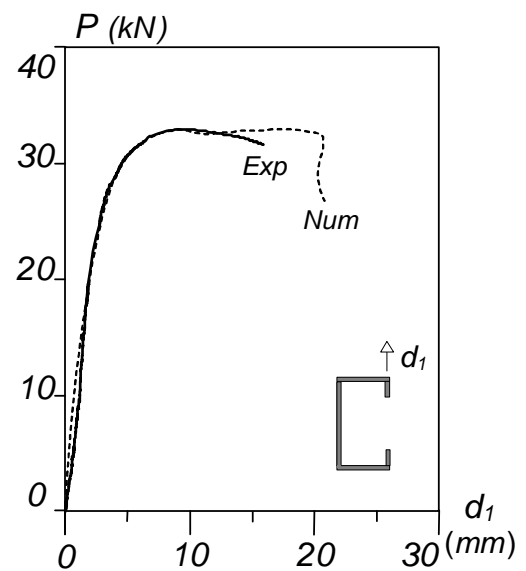

(a)
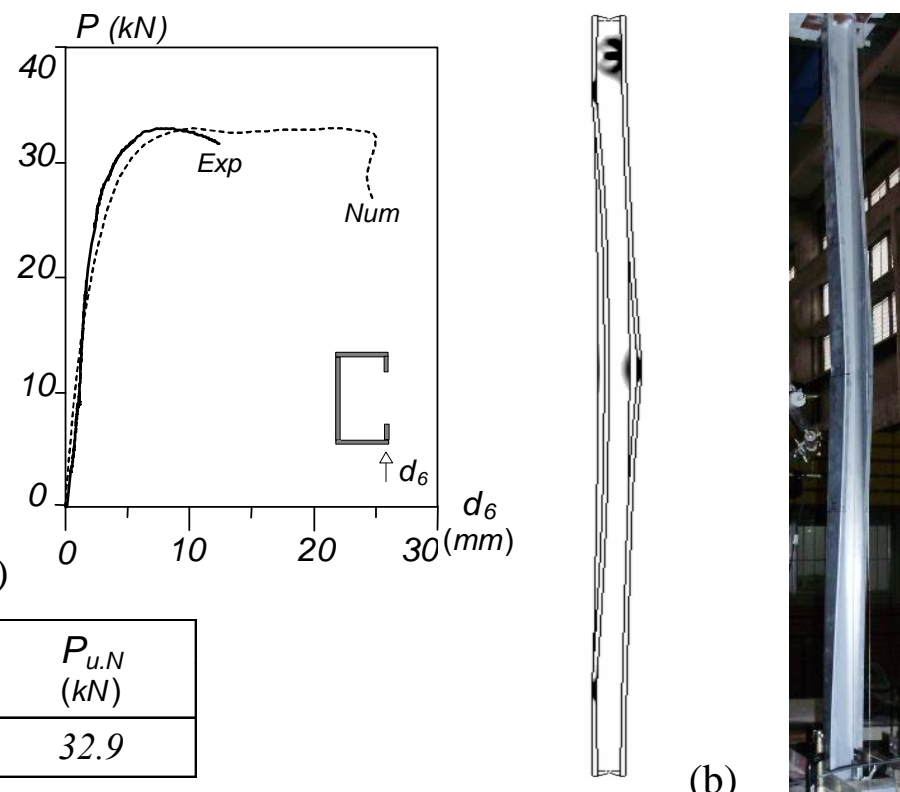

Figure 13. Numerical and Experimental Results

(a) Post-buckling Equilibrium Paths $P$ vs. $d_{1}$ and $P v s . d_{6}$, together with the Corresponding Ultimate Loads, and (b) Failure Mode Representations

\section{PRELIMINARY DESIGN CONSIDERATIONS}

Until the beginning of this century, the well-known Effective Width Method was the only universally accepted design procedure to estimate the ultimate strength of thin-walled cold-formed steel members affected by local (and later also distortional) buckling phenomena. However, the advent of increasingly more complex cross-section shapes (e.g., those exhibiting several lips and/or intermediate stiffeners) made the determination of their effective properties a very laborious and time-consuming task, thus paving the way for the development of the Direct Strength Method (DSM), originally proposed by Schafer and Peköz [4] and having its roots on earlier work carried out by Hancock and his collaborators at the University of Sydney. Besides overcoming the difficulties associated with the determination of the effective cross-section properties, the DSM also provides a rational and systematic framework for the design of thin-walled members with arbitrary cross-section shapes, loadings or failure modes - the ultimate strength prediction is obtained solely on the basis of the member elastic buckling and yield stresses. However, as pointed out by Schafer (e.g., Schafer [5]), further research is needed before the DSM approach can be successfully applied to members affected by interaction phenomena involving distortional buckling, namely that addressed in this work. 
Therefore, the aim of this section is to present some preliminary considerations concerning the applicability of the current DSM expressions to estimate the load-carrying capacity of cold-formed steel lipped channel columns affected by $\mathrm{L} / \mathrm{D} / \mathrm{G}$ mode interaction. It is worth noting that these considerations are based on the rather limited "data bank" of numerical and experimental ultimate strength values obtained in the course of the current and previous research efforts carried out by the authors. The numerical values concern elastic/perfectly-plastic steel $(E=210 \mathrm{GPa}, v=0.3)$ columns with (i) pinned (P) or fixed (F) end sections, (ii) critical-mode global initial imperfections (the most detrimental ones) with $L / 1000$ amplitude and (iii) three yield stresses $\left(f_{y}=235,355,520 \mathrm{MPa}\right)$ - the pinned-ended values were obtained in a previous $\mathrm{L} / \mathrm{D} / \mathrm{G}$ interaction investigation [22, 25], involving columns with $b_{w}=92 \mathrm{~mm}, b_{f}=65 \mathrm{~mm}$, $b_{l}=10 \mathrm{~mm}, t=1.2 \mathrm{~mm}$ and $L=152 \mathrm{~cm}$. The experimental results concern 9 tests carried out at COPPE - the ultimate loads measured are given in Table 1.

The DSM expressions correspond to "Winter-type" design curves, which (i) were calibrated against a large number of experimental and/or numerical results, and (ii) prescribe that the column nominal strengths against local, distortional and global failure $\left(P_{n l}, P_{n d}\right.$ and $\left.P_{n g}\right)$ are given by Schafer [5]

$$
\begin{aligned}
& \left\{\begin{array}{l}
P_{n l}=P_{y} \quad \text { if } \quad \lambda_{l} \leq 0.776 \\
P_{n l}=P_{y}\left(\frac{P_{c r l}}{P_{y}}\right)^{0.4}\left[1-0.15\left(\frac{P_{c r l}}{P_{y}}\right)^{0.4}\right] \quad \text { if } \quad \lambda_{l}>0.776
\end{array}\right. \\
& \left\{\begin{array}{l}
P_{n d}=P_{y} \quad \text { if } \quad \lambda_{d} \leq 0.561 \\
P_{n d}=P_{y}\left(\frac{P_{c r d}}{P_{y}}\right)^{0.6}\left[1-0.25\left(\frac{P_{c r d}}{P_{y}}\right)^{0.6}\right] \quad \text { if } \quad \lambda_{d}>0.561
\end{array}\right. \\
& \left\{\begin{array}{llll}
P_{n g}=P_{y} & 0.658^{\lambda_{g}^{2}} & \text { if } & \lambda_{g} \leq 1.5 \\
P_{n g}=P_{y} & \frac{0.877}{\lambda_{g}^{2}} & \text { if } & \lambda_{g}>1.5
\end{array}\right.
\end{aligned}
$$

where (i) $\lambda_{l}=\left(P_{y} / P_{c r l}\right)^{0.5}, \lambda_{d}=\left(P_{y} / P_{c r d}\right)^{0.5}$ and $\lambda_{g}=\left(P_{y} / P_{c r g}\right)^{0.5}$, (ii) $P_{y}$ is the squash load and (iii) $P_{c r l}$, $P_{c r d}$ and $P_{c r g}$ are the local, distortional and global (flexural, torsional or flexural-torsional) critical buckling loads. In order to capture possible local/global interaction effects, the current DSM approach replaces $P_{y}$ by $P_{n g}$ in Eq. 1 . In fact, $P_{n g}$ appears in the DSM expressions concerning local failure that are included in the most recent versions of the Australian/New Zealander [35] and North American [36] specifications for cold-formed steel structures.

Figures 14(a)-(d) show the variation of the $P_{u} / P_{y}$ stress ratios with the slenderness $\lambda_{d}$ (note that one has always $\lambda_{d} \approx \lambda_{l} \approx \lambda_{g}$ ) for the ultimate strength values of all the lipped channel column analysed numerically or tested experimentally. These figures also include five DSM "Winter-type" curves corresponding to (i) local (L), distortional (D) and global (G) column failure (Eqs. 1-3), (ii) local/global (L/G) (Eqs. 1 with $P_{y}$ replaced by $P_{n g}$ ) and (iii) distortional/global interactive failure (Eqs. 2 with $P_{y}$ replaced by $\left.P_{n g}\right)^{6}$. The observation of the results presented in Figures 14(a)-(d) leads to the following conclusions:

\footnotetext{
${ }^{6}$ Note that the DSM curve concerning distortional/global interactive failures has not yet been properly calibrated against experimental and/or numerical results. It was obtained through the same approach followed to handle the local/global interactive failures.
} 
(i) Both the numerical and experimental ultimate loads results fall below the predictions yielded by the individual (L, D and G) DSM design curves, which provides evidence of the occurrence of ultimate strength erosion due to the $\mathrm{L} / \mathrm{D} / \mathrm{G}$ mode interaction.

(ii) The DSM L/G curve provides (ii ${ }_{1}$ ) "almost perfect" predictions of the (numerical) pinned-ended column ultimate loads and $\left(\mathrm{ii}_{2}\right)$ conservative estimates of the numerical fixed-ended column ultimate loads - indeed, the latter are very close to the DSM global curve.

(iii) All but one of the 9 experimental ultimate load ratios (fixed-ended columns) fall below the DSM L/G curve. However, all of them are also nicely "aligned" in the close vicinity of the D/G curve, making it possible to say that this curve provides accurate and (practically always) safe estimates of the ultimate loads measured during the tests.

(iv) Although further numerical and experimental investigations are needed before definite conclusions can be drawn, these preliminary results suggest that the $D / G$ curve may serve as the basis for the development of a DSM design expression able to cover lipped channel columns experiencing local/distortional/global mode interaction.
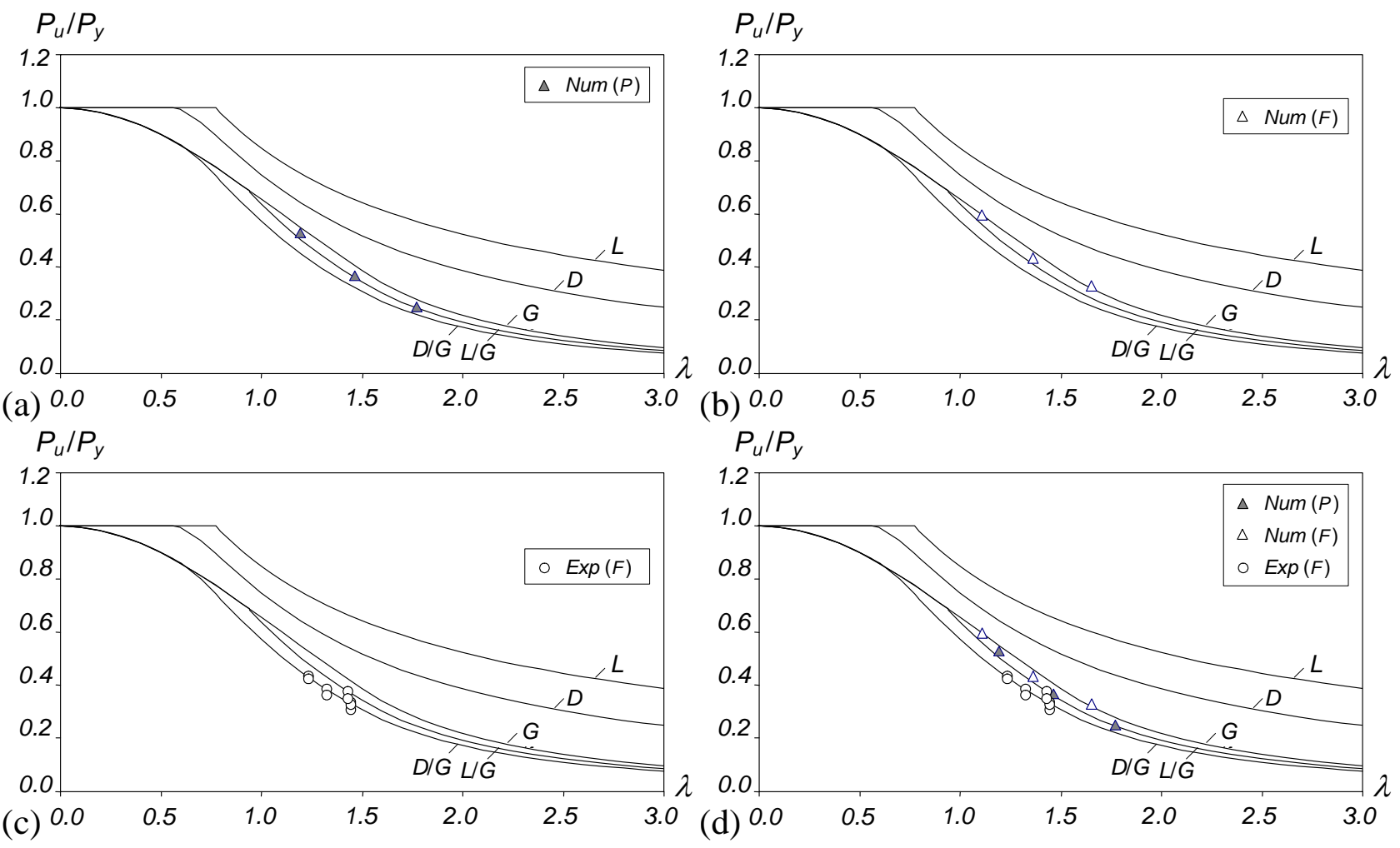

Figure 14. Variation of $P_{u} / P_{y}$ with $\lambda_{d}=\lambda_{l}=\lambda_{g}$ for the (a) Pinned-ended (Numerical Values), (b) Fixed-ended (Numerical Values) (c) Fixed-ended (Experimental Values) and (d) All (Numerical/Experimental Values) Lipped Channel Columns

\section{CONCLUSION}

This paper reported the available results of an ongoing investigation on the post-buckling behaviour and strength of fixed-ended cold-formed steel lipped channel columns experiencing local/distortional/global mode interaction, whose geometries were identified through "trial-and-error" buckling analyses. Initially, shell finite element elastic (mostly) and elastic-plastic post-buckling results concerning otherwise identical columns with critical-mode initial imperfections, exhibiting different configurations and sharing a common amplitude, were presented and discussed in detail. It was found that (i) global initial imperfections are 
the most detrimental ones and (ii) the $\mathrm{L} / \mathrm{D} / \mathrm{G}$ mode interaction causes noticeable column ultimate strength erosion - its quantification requires an extensive parametric study and is planned for the near future. Then, an overview of the experimental investigation currently under way at COPPE/UFRJ was presented - a full report will be available soon. After providing a brief account of the test program, set-up, procedure and results, the comparison between the experimental and numerical results concerning one column specimen were presented and discussed in some detail - a fairly good agreement was found. Finally, the paper closed with some preliminary considerations on the DSM design of cold-formed steel lipped channel columns affected by local/distortional/global mode interaction.

\section{REFERENCES}

[1] Prola, L.C. and Camotim, D., "On the Distortional Post-buckling Behavior of Cold-formed Lipped Channel Steel Columns”, Proceedings SSRC Annual Stability Conference, Seattle 2002, pp. 571-590.

[2] Silvestre, N. and Camotim, D., "Local-plate and Distortional Post-buckling Behavior of Cold-formed Steel Lipped Channel Columns with Intermediate Stiffeners”, Journal of Structural Engineering, ASCE, 2006, Vol. 132, No. 4, pp. 529-540.

[3] Batista, E.M., "Local-global Buckling Interaction Procedures for the Design of Cold-formed Columns: Effective Width and Direct Method Integrated Approach”, Thin-Walled Structures, 2009, Vol. 47, No. 11, pp. 1218-1231.

[4] Schafer, B.W. and Pekoz, T. "Direct Strength Prediction of Cold-formed Steel Members Using Numerical Elastic Buckling Solutions”, In: Shanmugam, N.E., Liew, J.Y.R., Thevendran, V. (Eds.). Thin-Walled Structures - Research and Development. Elsevier, 1998, pp. 137-144.

[5] Schafer, B.W., "Review: The Direct Strength Method of Cold-formed Steel Member Design", Journal of Constructional Steel Research, 2008, Vol. 64, No. 7-8, pp. 766-778.

[6] Schafer, B.W. and Peköz, T., "Laterally Braced Cold-formed Steel Members with Edge Stiffened Flanges”, Journal of Structural Engineering, 1999, ASCE, Vol. 125, No. 2, pp. 118-127.

[7] Ungureanu, V. and Dubina, D., "Recent Research Advances on ECBL Approach - Part I: Plastic-elastic Interactive Buckling of Cold-formed Steel Sections”, Thin-Walled Structures, 2004, Vol. 42, No. 2, pp. 177-194.

[8] Yang, D. and Hancock, G., "Compression Tests of High Strength Steel Columns with Interaction between Local and Distortional Buckling”, Journal of Structural Engineering, ASCE, 2004, Vol. 130, No. 12, pp. 1954-1963.

[9] Dinis, P.B., Camotim, D. and Silvestre, N., "FEM-based Analysis of the Local-plate/Distortional Mode Interaction in Cold-formed Steel Lipped Channel Columns”, Computers \& Structures, 2007, Vol. 85, No. 19-20, pp. 1461-1474.

[10] Hancock, G., Yap, D. and Yang, D., "Interaction Buckling in High Strength Cold-formed Steel Compression Members", Proceedings of $6^{\text {th }}$ International Conference on Steel \& Aluminum Structures (ICSAS’07), Beale, R. (Ed.), Oxford 2007, pp. 14-25.

[11] Silvestre, N., Camotim, D. and Dinis, P.B., "DSM Design of Fixed Lipped Channel Columns Against Local-plate/Distortional Interactive Buckling”, Proceedings of $6^{\text {th }}$ International Conference on Steel \& Aluminum Structures (ICSAS’07), Beale, R. (Ed.), Oxford 2007, pp. 752-759.

[12] Kwon, Y.B., Kim, B.S. and Hancock, G.J., "Compression Tests for the High Strength Cold-formed Steel Columns Undergoing Interaction between Local and Distortional Buckling”, Proceedings of Gregory J. Hancock Symposium, K. Rasmussen, T. Wilkinson (eds.), Sydney 2008, pp. 13-20. 
[13] Camotim, D., Dinis, P.B. and Silvestre, N., "Local/Distortional Mode Interaction in Lipped Channel Steel Columns: Post-buckling Behaviour, Strength and DSM Design”, Proceedings of Fifth International Conference on Thin-Walled Structures, Mahendran, M. (Ed.), Brisbane 2008, pp. 99-114.

[14] Kwon, Y.B., Kim, B.S. and Hancock, G.J., "Compression Tests of High Strength Cold-formed Steel Channels with Buckling Interaction”, Journal of Constructional Steel Research, 2009, Vol. 65, No. 2, pp. 278-289.

[15] Silvestre, N., Camotim, D. and Dinis, P.B., "Direct Strength Prediction of Lipped Channel Columns Experiencing Local-plate/Distortional Interaction”, Advanced Steel Construction An International Journal, 2009, Vol. 5, No. 1, 2009, pp. 45-67.

[16] Yapp, D. and Hancock, G.J., "Interaction of Local and Distortional Modes in Thin-walled Sections", Proceedings of Sixth International Conference on Advances in Steel Structures (ICASS’09), Chan, S.L. (Ed.), Hong Kong, 2009, pp. 35-48.

[17] Young, B., Camotim, D. and Silvestre, N., "Ultimate Strength and Design of Lipped Channel Columns Experiencing Local/Distortional Mode Interaction - Part I: Experimental Investigation", Proceedings of Sixth International Conference on Advances in Steel Structures (ICASS’09), Chan, S.L. (Ed.), Hong Kong, 2009, pp. 460-469.

[18] Silvestre, N., Camotim, D. and Young, B., "Ultimate Strength and Design of Lipped Channel Columns Experiencing Local/Distortional Mode Interaction - Part II: DSM Design Approach”, Proceedings of Sixth International Conference on Advances in Steel Structures (ICASS'09), Chan, S.L. (Ed.), Hong Kong, 2009, pp. 470-479.

[19] Dinis, P.B., Young, B. and Camotim, D., "On the Effect of Local/Distortional Mode Interaction on the Post-buckling Behaviour and Ultimate Strength of Fixed-ended Lipped Channel Columns", Proceedings of IJSSD Symposium on Progress in Structural Stability and Dynamics, Rasheed, H. (Ed.), Hong Kong, 2009, pp. 191-198.

[20] Silvestre, N., Camotim, D. and Dinis, P.B., "Direct Strength Approach to the Design of Lipped Channel Steel Columns Against Local/Distortional Interactive Buckling”, Submitted for Publication, 2010.

[21] Dinis, P.B. and Camotim, D., "Post-buckling Analysis of Cold-formed Steel Lipped Channel Columns Affected by Distortional/Global Mode Interaction”, Proceedings of SSRC Annual Stability Conference, Nashville, 2008, pp. 405-431.

[22] Dinis, P.B. and Camotim, D., "Local/Distortional/Global Buckling Mode Interaction in Cold-formed Steel Lipped Channel Columns", Proceedings of SSRC Annual Stability Conference, Phoenix, 2009, pp. 295-323.

[23] Dinis, P.B. and Camotim, D., "Coupled Instabilities with Distortional Buckling in Cold-formed Steel Lipped Channel Columns”, Thin-Walled Structures, Accepted for Publication, 2010.

[24] Dinis, P.B. and Camotim, D., "Post-buckling Behaviour and Strength of Cold-formed Steel Lipped Channel Columns Experiencing Distortional/Global Interaction”, Computers \& Structures, 2011, Vol. 89, No. 3-4, pp. 422-434.

[25] Dinis, P.B. and Camotim, D., "Local/Distortional/Global Buckling Mode Interaction in Simply Supported Cold-formed Steel Lipped Channel Columns”, International Journal of Structural Stability and Dynamics, Accepted for Publication, 2011.

[26] Dinis, P.B., Camotim, D., Batista, E.M. and Santos, E., "Local/Distortional/Global Mode Coupling in Fixed Lipped Channel Columns: Behaviour and Strength”, Proceedings of $6^{\text {th }}$ International Conference on Advances in Steel Structures (ICASS’09), Chan, S.L. (Ed.), Hong Kong, 2009, pp. 19-34.

[27] Rossi, B., Jaspart, J.-P. and Rasmussen, K.R., "Combined Distortional and Overall Flexural-Torsional Buckling of Cold-Formed Stainless Steel Sections: Experimental Investigations”, Journal of Structural Engineering, ASCE, 2010, Vol. 136, No. 4, pp. 354-360. 
[28] Dinis, P.B. and Camotim, D., "Local/Distortional/Global Buckling Mode in Cold-formed Steel Rack-section Columns”, Proceedings of SSRC Annual Stability Conference, Orlando 2010, pp. 481-504.

[29] Simulia Inc., Abaqus Standard (Version 6.7-5), 2008.

[30] Dinis, P.B. and Camotim, D., "On the Use of Shell Finite Element Analysis to Assess the Local Buckling and Post-buckling Behaviour of Cold-formed Steel Thin-walled Members", Proceedings of III European Conference on Computational Mechanics: Solids, Structures and Coupled Problems in Engineering, (III ECCM), C.A.M. Soares et al. (Eds.), Lisboa, 2006, pp. 689. (Full Paper in CD-RoM Proceedings)

[31] Camotim, D., Silvestre, N., Gonçalves, R. and Dinis, P.B., "GBT Analysis of Thin-walled Members: New Formulations and Applications”, Thin-Walled Structures: Recent Advances and Future Trends in Thin-Walled Structures Technology, Loughlan, J. (Ed.), Bath, 2004, pp. 137-168.

[32] Bebiano, R., Silvestre, N. and Camotim, D., "GBTUL 1.0 $\beta$ - Code for Buckling and Vibration Analysis of Thin-Walled Members”, Freely Available at $h t t p: / / w w w . c i v i l . i s t . u t l . p t / g b t, 2008$.

[33] Bebiano, R., Silvestre, N. and Camotim, D., "GBTUL - A Code for the Buckling Analysis of Cold-formed Steel Members", Proceedings of $19^{\text {th }}$ International Specialty Conference on Recent Research and Developments in Cold-Formed Steel Design and Construction, LaBoube, R., Yu, W.-W. (Eds.), St. Louis, 2008, pp. 61-79.

[34] Young, B. and Rasmussen, K.J., "Shift of Effective Centroid in Channel Columns", Journal of Structural Engineering, ASCE, 1999, Vol. 125, No. 5, pp. 524-531.

[35] AS/NZS4600, Cold-Formed Steel Structures, Australian Standard/New Zealand Standard 4600, Standards Australia, Sydney, 2005.

[36] NAS, North American Specification for the Design of Cold-Formed Steel Structural Members (AISI-S100-07), American Iron and Steel Institute (AISI), Washington DC, 2007. 